Research Paper

\title{
Enrichment of Prostate Cancer Stem-Like Cells from Human Prostate Cancer Cell Lines by Culture in Se- rum-Free Medium and Chemoradiotherapy
}

Lei Wang${ }^{1}$, Xing Huang ${ }^{2}$, Xinmin Zheng ${ }^{1,}$, Xinghuan Wang ${ }^{1}$, Shiwen Li1, Lin Zhang1, Zhonghua Yang1, Zhiping Xia ${ }^{1}$

1. Department of Urology, Zhongnan Hospital, Wuhan University, Wuhan 430071, China.

2. Department of Urology, Xiangyang Central Hospital, Hubei University of Arts and Science, Xiangyang 441021, China.

$\square$ Corresponding author: Xinmin Zheng, Department of Urology, Zhongnan Hospital, Wuhan University, Wuhan 430071, China. Tel: +86 027 67813104. Fax: +86 027 67813104. e-mail: zxmsurgeon@126.com

(c) Ivyspring International Publisher. This is an open-access article distributed under the terms of the Creative Commons License (http://creativecommons.org/ licenses/by-nc-nd/3.0/). Reproduction is permitted for personal, noncommercial use, provided that the article is in whole, unmodified, and properly cited.

Received: 2013.0I.10; Accepted: 2013.05.09; Published: 2013.05.15

\begin{abstract}
The discovery of rare subpopulations of cancer stem cells (CSCs) has created a new focus in cancer research. As CSCs demonstrate resistance to chemoradiation therapy relative to other cancer cells, this allows the enrichment of CSC populations by killing apoptosis-susceptible cancer cells. In this study, three commonly used human prostate cancer (PCa) cell lines (DUI45, PC-3 and LNCaP) were examined for their expression of the putative stem cell markers CDI33 and CD44 via flow cytometric analysis. Under normal culture conditions, $\mathrm{CDI} 33^{+} / \mathrm{CD} 44^{+}$cells were only present in the DUI 45 cell line, and comprised only a minor percentage $(0.1 \% \pm 0.01 \%)$ of the total

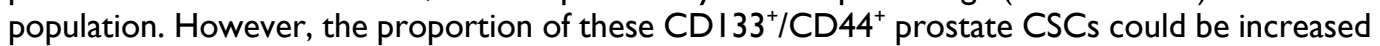
in these cell lines via culture in serum-free medium (SFM), or through chemotherapy or radiotherapy. Indeed, after culture in SFM, the proportion of CDI33 $/ \mathrm{CD}_{4} 4^{+}$cells in DUI45 and PC-3 had increased to $10.3 \%$ and $3.0 \%$, respectively. Moreover, the proportion had increased to $9.8 \%$ enriched by chemotherapy and $3.5 \%$ by radiotherapy in DUI 45 . Colony-formation tests, cell invasion assays, and tumor xenografts in $B A L B / c$ nude mice were used to evaluate the stem cell properties of $\mathrm{CDI} 33^{+} / \mathrm{CD} 44^{+} \mathrm{PCa}$ cells that were isolated via fluorescence-activated cell sorting (FACS). CDI $33^{+} / \mathrm{CD} 44^{+}$cells had an enhanced colony-formation capability and invasive ability in vitro, and displayed greater tumorigenic properties in vivo. These results demonstrate the presence of $\mathrm{CDI} 33^{+} / \mathrm{CD}_{4} 4^{+}$prostate CSCs in established $\mathrm{PCa}$ cell lines and that populations of these cells can be enriched by culture in SFM or chemoradiotherapy. Finding novel therapies to override chemoradiation resistance in the prostate CSCs is the key to improve long-term results in PCa management.
\end{abstract}

Key words: Cancer stem cells; Prostate cancer; Serum-free medium culture; Chemotherapy; Radiotherapy.

\section{Introduction}

Prostate cancer (PCa) is the second most frequently diagnosed cancer and the sixth leading cause of cancer death in males, accounting for $14 \%(903,500)$ of total new cancer cases and 6\% $(258,400)$ of total cancer deaths in males in 2008 [1]. Indeed, PCa is ex- pected to account for $29 \%(241,740)$ of incident cases among men in 2012 [2]. Although conventional therapies are effective in the initial phase of treatment, $\mathrm{PCa}$ often eventually progresses to form invasive, drug-resistant metastatic cancers upon relapse [3]. 
The cancer stem cells (CSCs) hypothesis postulates that a small subpopulation of cancer cells drive tumor growth and metastasis, and that CSCs are more resistant to toxic injuries and chemoradiation therapy than differentiated daughter cells [4, 5]. Therefore, chemoradiotherapy-resistant CSCs have the potential to regrow, leading to the relapse into cancer following apparently successful treatment [6]. Researchers have isolated CSCs by identifying cell surface markers, usually a specific molecule or combination of molecules, in a variety of solid tumors including breast cancer [7], brain tumors [8] and lung cancer [9]. Prostate CSCs express a number of the same markers as prostate stem cells, such as CD44, CD133, integrins and Sca-1. Putative prostate CSCs have been isolated from human PCa biopsies based on the expression of $\mathrm{CD} 44^{+} / \mathrm{a}_{2} \beta_{1} \mathrm{hi}^{\mathrm{C}} / \mathrm{CD} 133^{+}$cell surface markers, and these cells are able to self-renew in vitro [10]. The identification of prostate CSCs provides a powerful tool in the investigation of the tumorigenic process and development of therapies that target stem cells.

The population of CSCs within a tumor is small. Current methods for sorting prostate CSCs are mainly based on $\mathrm{CD}_{133^{+}} / \mathrm{CD} 44^{+}$expression or side population (SP) cells. However, cells obtained from the $\mathrm{CD} 133^{+} / \mathrm{CD}_{4} 4^{+}$subpopulation or SP cells are very rare or even undetectable in prostate, which severely hinders the isolation and purification of prostate CSCs.

CSCs are more resistant to apoptosis induced by stress, such as chemotherapy and/or radiotherapy, with high expression of anti-apoptotic molecules and reduced expression of pro-apoptotic genes [11, 12]. In addition, CSCs exhibit preferential activation of the DNA damage checkpoint response and increased DNA repair capacity, which may also contribute to their chemoradiation resistance [13]. Therefore, it is reasonable to speculate that chemoradiotherapy could effectively enrich CSCs within the tumor by eliminating chemo- and radio-sensitive cells.

In the present study, three commonly used human PCa cell lines (DU145, PC-3 and LNCaP) were examined for their expression of the putative stem cell markers CD133 and CD44. The serum-free sphere culture method, chemotherapy, and radiation therapy used to enrich prostate CSCs are described in detail, while the tumorigenic and stem cell properties of these prostate CSCs are also investigated.

\section{Materials and methods}

\section{Cell culture}

All the cell lines examined were derived from prostate carcinomas. DU145, PC-3, and LNCaP cells were obtained from the Cell Bank of the Chinese
Academy of Sciences (Shanghai, China). Cells were cultured in RPMI-1640 supplemented with $10 \%$ heat-inactivated fetal bovine serum (Gibco/Invitrogen, Australia), and $1 \%$ penicillin/streptomycin (Invitrogen) at $37^{\circ} \mathrm{C}$ in a humidified incubator in the presence of $5 \% \mathrm{CO}_{2}$.

\section{Flow cytometric analysis}

Flow cytometric analysis was used to detect

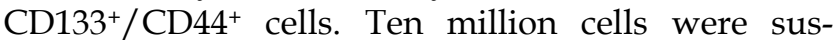
pended in PBE (PBS containing 0.5\% bovine serum albumin and 2 mM EDTA, $\mathrm{pH}$ 7.2) in a volume of 80 $\mu \mathrm{l}$ for antibody labeling. CD133/2(293C3)-PE (130-090-853) and CD44-FITC (130-095-195) antibodies were obtained from Miltenyi Biotec $\mathrm{GmbH}$ (Germany) and used to label cells using the manufacturer's instructions. Flow cytometric analysis was performed using a Beckman Coulter FC 500 MCL/MPL counter fitted with a $488 \mathrm{~nm}$ laser. At least four independent experiments were carried out on each cell line. $\mathrm{CD}_{133}{ }^{+} / \mathrm{CD} 44^{+}$cells were isolated from a DU145 cell population with a Beckman Coulter MoFlo XDP flow cytometer.

\section{Serum-free medium (SFM) culture enrich- ment}

DMEM/F12 (1:1) basal medium (Hyclone SH 30023.01B) was supplemented with $20 \mathrm{ng} / \mathrm{ml}$ human epidermal growth factor (130-093-825, Miltenyi Biotec $\mathrm{GmbH}), 20 \mathrm{ng} / \mathrm{ml}$ basic fibroblast growth factor (130-093-837, Miltenyi Biotec $\mathrm{GmbH}$ ), and $2 \mathrm{ng} / \mathrm{ml}$ recombinant human leukemia inhibitory factor (\#LIF1010, Millipore Corporation, USA). Sub-confluent cells were collected and maintained in this defined SFM. The medium was refreshed every second day, although it should be noted that during the initial treatment period, the majority of cells died off. Cells were collected for flow cytometric analysis after two weeks. All experiments were performed in quadruplicate wells.

\section{Chemotherapy enrichment}

Sub-confluent DU145 cells were treated with 0.1 $\mu \mathrm{M}$ docetaxel. The medium was changed after $6 \mathrm{~h}$ to enhance cell survival. Three days later, the surviving cells were collected for flow cytometric analysis. In order to select the proper concentration of docetaxel, sub-confluent DU145 cells were treated with 0.001 $\mu \mathrm{M}, 0.01 \mu \mathrm{M}, 0.1 \mu \mathrm{M}$ and $1.0 \mu \mathrm{M}$ docetaxel for $24-72 \mathrm{~h}$, and the inhibiting effect of docetaxel on the proliferation of DU145 cells was observed by the methyl thiazolyl tetrazolium (MTT) assay. The results showed that the inhibitory rate was positively related to the concentration of docetaxel (Figure 1). Using higher concentrations of drug did not allow flow cytometric 
analysis to be performed due to the high levels of cell death. But using the concentrations less than $0.1 \mu \mathrm{M}$, we couldn't enrich the prostate cancer stem cells effectively. Four independent experiments were performed.



Figure I. Effects of docetaxel with increasing concentrations $(0.00 \mathrm{I}-\mathrm{I}$ $\mu \mathrm{M})$ on the proliferation of DUI45 cells. The proliferative response was assessed by MTT assay.

\section{Radiotherapy enrichment}

Sub-confluent DU145 cells were irradiated with 4 Gy twice a week using a linear accelerator with electron cut-off energy of $10 \mathrm{MeV}$ (Siemens primus $\mathrm{H})$. After two weeks of radiation treatment, surviving cells were harvested for flow cytometric analysis. Although once or twice weekly radiation doses of 2 Gy, 4 Gy, 6 Gy, 8 Gy, and 10 Gy were trialed, 4 Gy twice a week was chosen as this approach rendered the surviving cells suitable for flow cytometric analysis. The higher dose of radiation resulted in the higher levels of cell death, which would be unsuitable for flow cytometric analysis. However, the lower dose of radiation couldn't enrich the prostate cancer stem cells effectively. All experiments were conducted a minimum of three times.

\section{Colony formation assay}

Isolated $\mathrm{CD}_{133^{+}} / \mathrm{CD} 44^{+}$DU145 cells and parental DU145 cells were cultured in 6-well plates (Corning, New York, USA) at 200 cells per well in $2 \mathrm{ml}$ medium. After 14 days, colonies with $>50$ cells were scored. Colony-formation efficiency (CFE) was defined as the percentage of cells that had formed clones. The experiments were performed in triplicate.

\section{Cell invasion assay}

Cell invasion experiments were performed using
Bio-Coat cell migration chambers (Becton Dickinson, USA), which consist of a 24-well companion plate with cell culture inserts containing filters of $8 \mu \mathrm{m}$ pores. Filters were coated with a basement membrane Matrigel $\left(37 \mu \mathrm{g} /\right.$ filter). Isolated $\mathrm{CD} 133^{+} / \mathrm{CD} 44^{+}$ DU145 cells and parental DU145 cells were seeded into the upper inserts $1.5 \times 10^{4}$ cells per insert in $150 \mu \mathrm{l}$ of serum-free RPMI-1640. Outer wells were filled with $600 \mu \mathrm{l}$ of RPMI-1640 containing $10 \%$ FBS as a chemoattractant. Cells were incubated at $37{ }^{\circ} \mathrm{C}$ with $5 \% \mathrm{CO}_{2}$ for $48 \mathrm{~h}$. The non-invading cells were gently removed and the invading cells on the under surface of the filter were fixed and stained. The membranes were mounted on glass slides, and the cells from five random microscopic fields were counted. Four independent experiments were performed.

\section{Xenograft tumorigenicity assay}

Six- to eight-week-old male BALB/c nude mice were purchased from Hunan SLK Laboratory Animal Center (Hunan, China; animal quality certificate No. SCXK [Xiang] 2009-0004) and housed under standard conditions. After one week of adaptation, the animals were used for in vivo studies, and the protocols were approved by the Animal Care Committee of Wuhan University. For cancer cell xenograft experiments, isolated CD133 ${ }^{+} / \mathrm{CD} 44^{+}$DU145 cells $\left(1 \times 10^{4}\right)$ and parental DU145 cells $\left(1 \times 10^{6}\right)$ were washed with PBS, resuspended in SFM, and injected subcutaneously into the left flank of the mice ( $n=10 /$ group). Tumor formation was monitored from one week after inoculation and tumor growth was measured twice weekly using Vernier calipers. Tumor volume (TV) was calculated using the following formula: TV $\left(\mathrm{mm}^{3}\right)=a^{2} \times$ $b \times 0.52$, where $a$ and $b$ were the shortest and longest diameters, respectively. Tumors measuring at least 5 $\mathrm{mm}$ in diameter were considered to be a positive take. After eight weeks, mice were euthanized and tumor formation was assessed. The tumor specimens were fixed in $4 \%$ paraformaldehyde, embedded in paraffin, and cut into 5- $\mu \mathrm{m}$ thick slides. The slides were then stained with hematoxylin and eosin. The expression of CD133 and CD44 was evaluated by immunofluorescence staining.

\section{Statistical analysis}

The SPSS software package, version 11.5 (SPSS, Inc, Chicago, IL, USA), was used for statistical analysis. Statistical analysis was performed using a student's $t$ test for continuous variables, and a $\chi^{2}$ test for categorical variables. Data of flow cytometry were expressed as the arithmetic mean. Other data were expressed as mean \pm standard deviation (SD), and $p<$ 0.05 was considered statistically significant. 


\section{Results}

CDI33+/CD44+ cells were only detected in DUI45 under normal culture conditions

Of the three PCa cell lines examined, $\mathrm{CD} 133^{+} / \mathrm{CD} 44^{+}$cells were only found to occur among DU145 cells under normal culture conditions, and $\mathrm{CD} 33^{+} / \mathrm{CD} 44^{+}$cells constituted only a small fraction $(0.1 \% \pm 0.01 \%)$ of total DU145 cells (Figure 2B). In $\mathrm{LNCaP}$ and PC-3 cell lines, $\mathrm{CD} 133^{+} / \mathrm{CD}_{4} 4^{+}$cells were not detected in flow cytometric analysis.

\section{CDI $33^{+} / \mathrm{CD}_{4} 4^{+}$cells were detected in PC-3 and DUI 45 after SFM enrichment}

When cultured in the defined SFM, the surviving DU145 and PC-3 cells formed suspended spheres of cells (Figure 3), and the proportion of $\mathrm{CD} 133^{+} / \mathrm{CD} 44^{+}$ cells in each cell line was significantly increased. The proportion of $\mathrm{CD}_{133}{ }^{+} / \mathrm{CD} 44^{+}$cells in DU145 and PC-3 had increased to $10.3 \%$ and $3.0 \%$, respectively (Figure $2 \mathrm{C}$ and $\mathrm{D})$. In contrast, $\mathrm{LNCaP}$ cells did not form obvious suspension spheres following culture in SFM and no $\mathrm{CD} 133^{+} / \mathrm{CD} 44^{+}$cells were detected by flow cytometric analysis.

\section{Three methods for enriching prostate CSCs in DUI45}

After culture in defined SFM, the proportion of CD133 ${ }^{+} / \mathrm{CD}_{4} 4^{+}$cells in the DU145 cell population increased to $10.3 \%$ (Figure 2C). Chemotherapy and radiotherapy also increased the proportion of $\mathrm{CD}_{133}{ }^{+} / \mathrm{CD}_{4}{ }^{+}$cells in DU145 cultures to $9.8 \%$ (Figure $2 \mathrm{E}$ ) and $3.5 \%$ (Figure $2 \mathrm{~F}$ ), respectively. Thus, the percentage of $\mathrm{CD}_{133^{+}} / \mathrm{CD} 44^{+}$cells among DU145 cells treated with any of the three enrichment methods was significantly increased compared to cell populations in serum-supplemented medium (SSM), demonstrating that chemotherapy and radiation therapy, as well as culture in SFM, are effective approaches for enriching prostate CSCs.

\section{CDI33+/CD44+ DUI 45 cells displayed high clonogenicity and increased invasiveness}

Although CD133 ${ }^{+} / \mathrm{CD} 44^{+}$cells only represented a small subpopulation of DU145 cells in normal culture conditions, they could be enriched using defined
SFM and then isolated by fluorescence-activated cell sorting (FACS). Thus, increasing the number of $\mathrm{CD}_{133}{ }^{+} / \mathrm{CD}_{4} 4^{+}$cells to enhance efficient sorting of these cells by FACS allowed us to compare the ability of $\mathrm{CD}_{133}{ }^{+} / \mathrm{CD} 44^{+}$DU145 cells to form colonies relative to the parental DU145 cells. The CFE of $\mathrm{CD} 133^{+} / \mathrm{CD}_{4} 4^{+}$cells $(68.5 \pm 4.7 \%)$ was 3.5 -fold greater than that of parental cells $(19.7 \pm 3.4 \%)(p<0.001)$. Furthermore, as measured by a $48 \mathrm{~h}$ in vitro invasion assay, a four-fold greater proportion of $\mathrm{CD}_{133}+\mathrm{CD}_{4}{ }^{+}$cells migrated through the Matrigel-coated membrane compared to parental DU145 cells (Figure $4, \mathrm{CD}_{133^{+}} / \mathrm{CD} 44^{+}$cells versus the parental cells, $416 \pm 47$ versus $109 \pm 24, p<0.001$ ).

\section{CDI33+/CD44+ DUI45 cells are more tumor- igenic in vivo}

According to the American Association for Cancer Research (AACR) Workshop on Cancer Stem Cells of 2006, the orthotopic xenograft assay is considered the gold standard for the identification of CSCs [14]. In our xenograft model, isolated

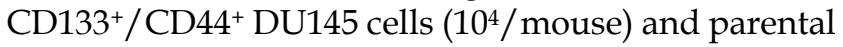
DU145 cells $\left(10^{6} /\right.$ mouse) were subcutaneously injected into nude mice ( $\mathrm{n}=10 /$ group). Our results showed that $\mathrm{CD} 133^{+} / \mathrm{CD} 44^{+}$cells initiated significantly larger tumors (10/10 observations) than parental DU145 cells (5/10 observations) (Figure 5). Tumors originating from $\mathrm{CD} 133^{+} / \mathrm{CD} 44^{+}$cells developed earlier and faster than those from parental cells, suggesting that $\mathrm{CD} 133^{+} / \mathrm{CD} 44^{+}$cells have enhanced tumorigenic potential relative to parental cells in nude mice (Table 1).

Table I. Tumor-formation ability of $\mathrm{CDI} 33^{+} / \mathrm{CD} 44^{+}$ DUI 45 cells and parental DUI 45 cells

\begin{tabular}{lllll}
\hline & \multicolumn{4}{c}{ Tumor-formation ratio } \\
\cline { 2 - 5 } & $1 \mathrm{~W}$ & $2 \mathrm{~W}$ & $4 \mathrm{~W}$ & $8 \mathrm{~W}$ \\
\hline CD133 $^{+} \mathrm{CD}_{4}{ }^{+}$cells $(\mathrm{n}=10)$ & $2 / 10$ & $7 / 10$ & $10 / 10$ & $10 / 10$ \\
Parental cells $(\mathrm{n}=10)$ & $0 / 10$ & $1 / 10$ & $4 / 10$ & $5 / 10$ \\
$p$ value & 0.474 & 0.020 & 0.011 & 0.033 \\
\hline
\end{tabular}

Tumor-formation ratio is expressed as the number of tumors formed to the number of mice injected. $p$ values $<0.05$ are considered statistically significant. 

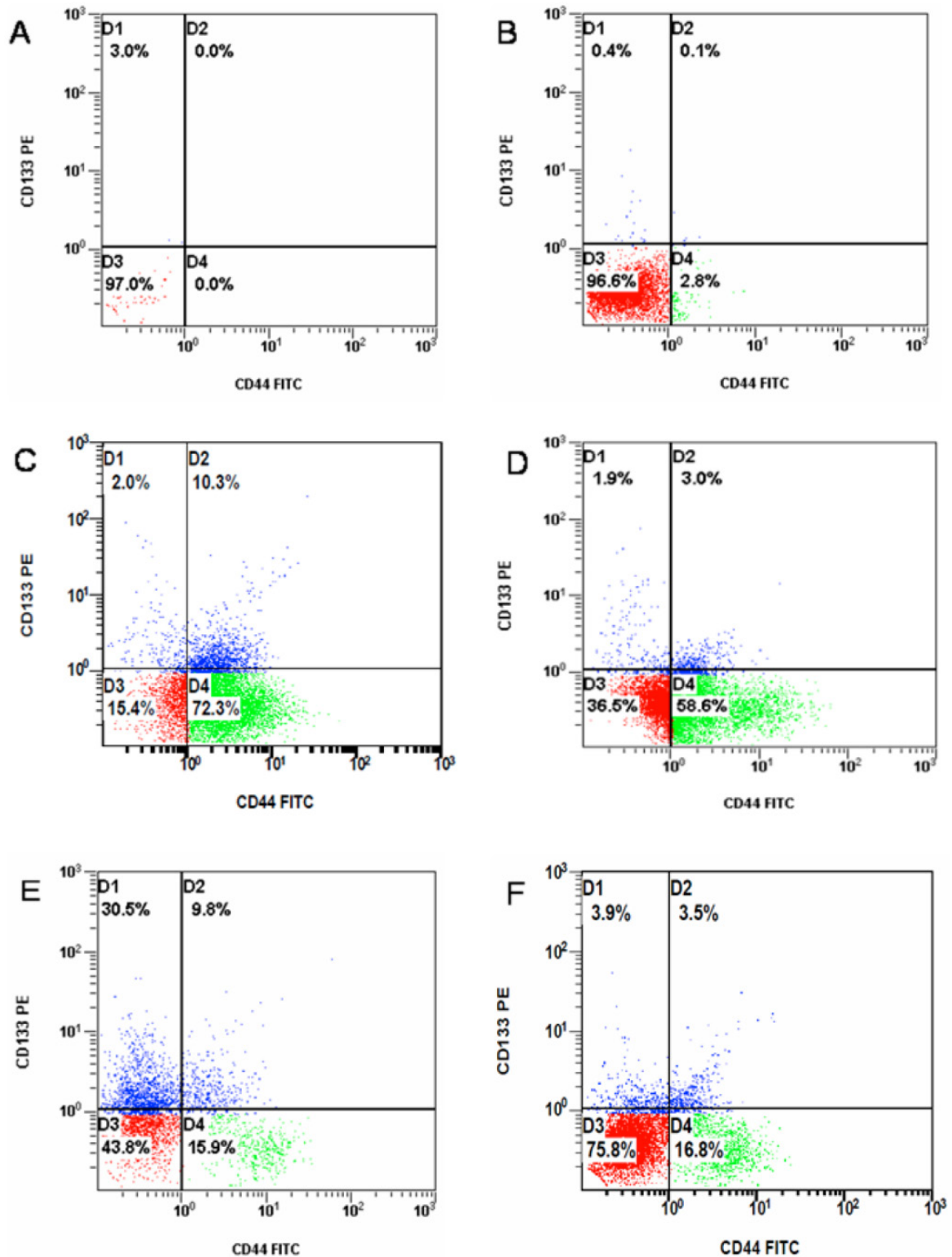

Figure 2. Flow cytometric analysis for the CDI $33^{+} / \mathrm{CD} 44^{+}$stem cell markers in three PCa cell lines. (A) isotype control, (B) DUI 45 cells cultured in SSM showing a small population of $\mathrm{CDI} 33^{+} / \mathrm{CD} 44^{+}$cells $(0.1 \%)$, (C) the CDI33 $/ \mathrm{CD} 44^{+}$DUI 45 cell population after SFM enrichment (I0.3\%), (D) the $\mathrm{CDI} 33^{+} / \mathrm{CD} 44^{+} \mathrm{PC}-3$ cell population after SFM enrichment (3.0\%), (E) the CDI33 $/$ CD $44^{+}$DUI 45 cell population after chemotherapy enrichment (9.8\%), (F) the $\mathrm{CDI} 33^{+} / \mathrm{CD}_{4} 4^{+} \mathrm{DUI} 45$ cell population after radiotherapy enrichment $(3.5 \%)$.

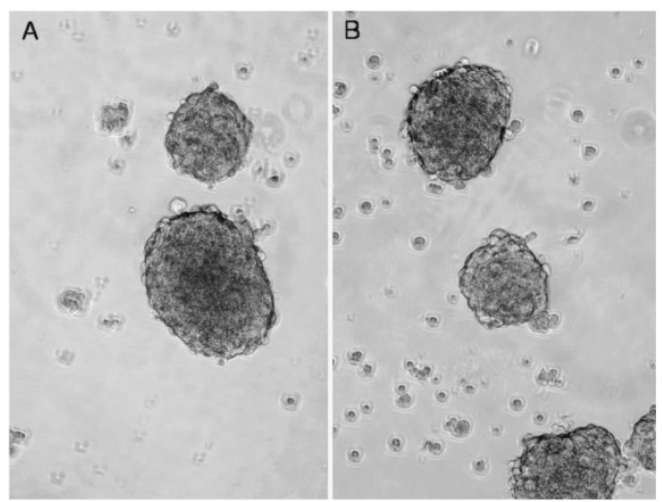

Figure 3. Serum-free medium (SFM) culture enrichment. Stem-like cells in PC-3 (A) and DUI45 (B) can be cultured as suspension spheres in defined SFM. Images were taken using a contrast microscope at magnifications of $200 \times$. 

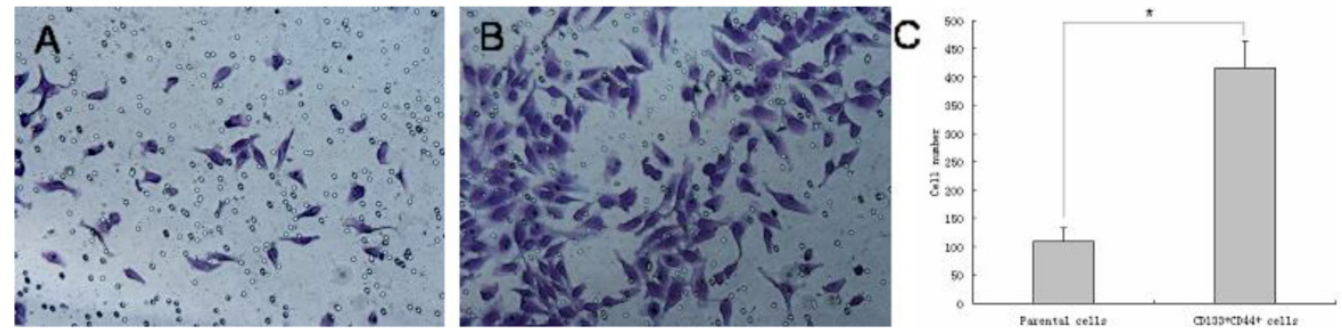

Figure 4. Cell invasion assay of $\mathrm{CDI} 33^{+} / \mathrm{CD} 44^{+} \mathrm{DUI} 45$ cells. CDI $33^{+} / \mathrm{CD} 44^{+}$cells isolated from DUI 45 cultures have increased migratory and invasive capacities. (A) Parental DUI 45 cells, (B) CDI $33^{+} / \mathrm{CD} 44^{+}$cells, (C) CDI $33^{+} / \mathrm{CD} 44^{+}$cells showing a 4 -fold increase in the number of cells migrating through a Matrigel-coated membrane compared to parental cells $\left(C D I 33^{+} / C D 44^{+}\right.$cells versus the parental cells, $416 \pm 47$ versus $\left.109 \pm 24, * p<0.001\right)$.
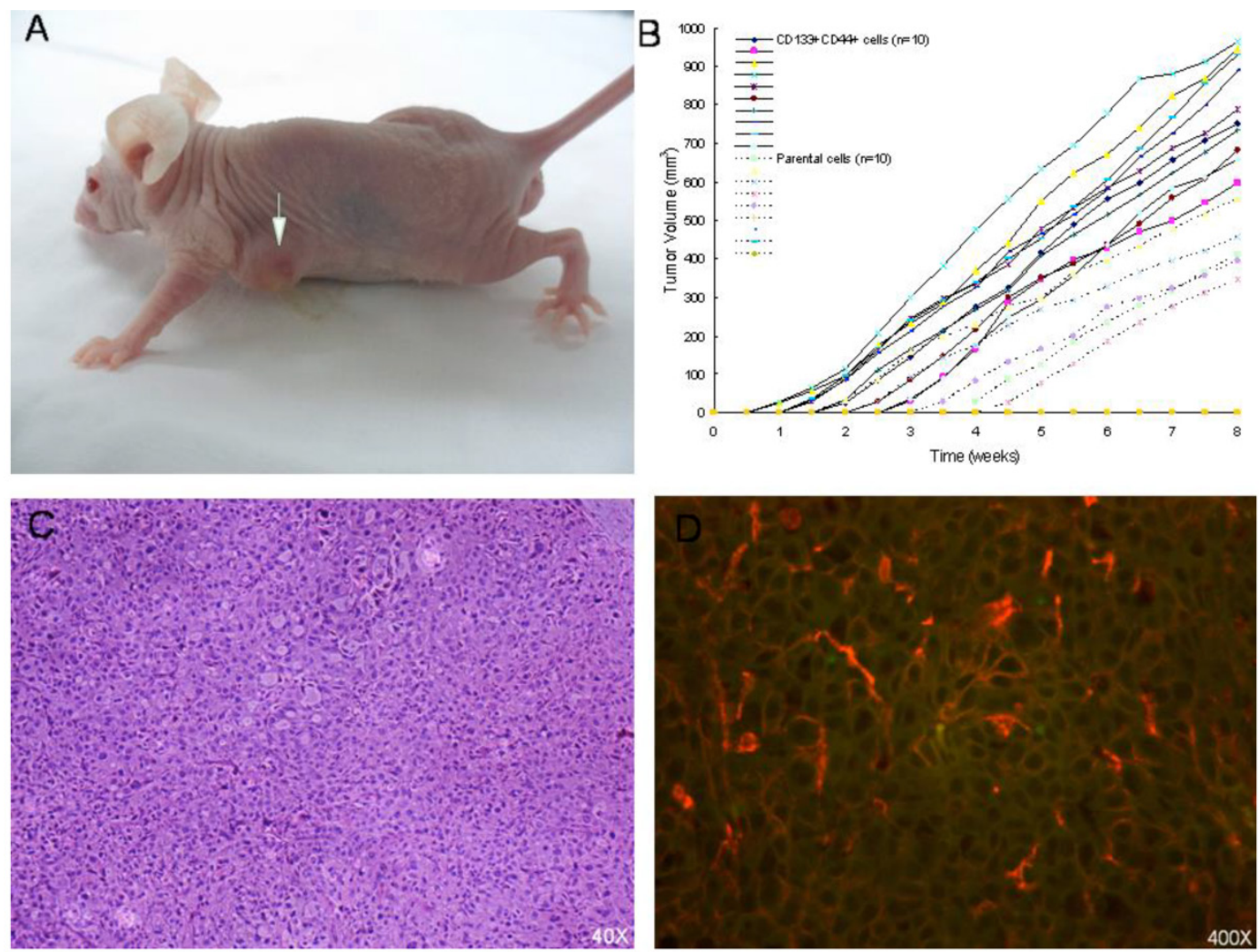

Figure 5. (A) Growths in $\mathrm{BALB} / \mathrm{c}$ nude mice after inoculation with $\mathrm{CDI} 33^{+} / \mathrm{CD} 44^{+}$cells taken from DUI 45 cultures. (B) Xenograft tumor growth curve for week I to 8 for all mice. At 8 weeks, xenograft tumor volume in CDI33 $/ C D 44^{+}$DUI45 cells was bigger than that of parental DUI45 cells $\left(\mathrm{CDI} 33^{+} / \mathrm{CD} 44^{+}\right.$cells versus the parental cells, $813.26 \pm 122.66 \mathrm{~mm}^{3}$ versus $\left.443.87 \pm 73.17 \mathrm{~mm}^{3}, * p<0.00 \mathrm{I}\right)$. (C) Histological analysis of subcutaneous tumors using hematoxylin and eosin staining shows cancer cell-specific features (irregularly packed tumor cells, hyperchromatic nuclei, prominent nucleoli and many mitotic cells). (D) Immunofluorescence double-staining visualized by confocal microscopy. CDI33 is shown in red and CD44 in green.

\section{Discussion}

In 2006, a consensus definition resulting from the Cancer Stem Cell Workshop of the AACR was published describing CSCs as "cells within a tumor that possess the capacity for self-renewal and that can cause the heterogeneous lineages of cancer cells that constitute the tumor" [14]. Indeed, there is increasing evidence that the initiation, growth, recurrence, and metastasis of cancers are related to the behavior of CSCs; thus, PCa research is currently focusing on CSCs to gain a better understanding of the mechanisms of tumor initiation, progression, and metastasis, which will assist in treating PCa patients more effectively.

Prostate CSCs express a number of the same markers as prostate stem cells, such as CD44, CD133, integrins, and Sca-1. Using CD133 as a positive selection marker for enrichment, Richardson and co-workers found that $\mathrm{CD}_{133^{+}}$cells from several prostatic tissues had greater proliferative and invasive ability [15]. Putative prostate CSCs characterized by cell surface expression of CD $44^{+} / \mathrm{a}_{2} \beta_{1} \mathrm{hi}^{\mathrm{Ci}} \mathrm{CD} 133^{+}$have been isolated from human PCa biopsies, and these cells were able to self-renew in vitro [10]. Prostate CSCs were also isolated from DU145 cell line with 
$\mathrm{CD} 44^{+} / \mathrm{a}_{2} \beta_{1}{ }^{\text {hi }} / \mathrm{CD} 133^{+}$markers [16] and human telomerase reverse transcriptase-immortalized primary tumor-derived prostate epithelial cell lines with CD133 ${ }^{\text {hi }}$ phenotype [17], respectively. In addition, a $\mathrm{CD}_{4}{ }^{+}$population from xenograft tumors and cell lines displayed enhanced proliferative potential and tumor-initiating ability in vivo [18]. Therefore, we examined CD133 expression, in combination with CD44, to identify and select prostate CSCs from several human PCa cell lines.

With respect to PCa research, it is unfortunate that the CSCs population in the tumor is small. The study of CSCs in the PCa, as in other complex tissues, is critically dependent on the availability of pure cell populations, a situation complicated by the heterogeneity of prostate tumors [19]. When cultured in RPMI-1640 supplemented with $10 \%$ FBS, only a small population $(0.1 \%)$ of $\mathrm{CD} 44^{+} / \mathrm{a}_{2} \beta_{1} \mathrm{hi}^{\mathrm{h}} / \mathrm{CD} 133^{+}$cells could be isolated from human PCa biopsies [10]. This inability to isolate sufficient numbers of stem cells severely limits research into prostate CSCs.

Sphere formation is increasingly used as a method for enriching stem cells as it relies on their characteristic anchorage-independent growth. Thus, CSCs can form spheres in vitro in serum-free suspension cultures. The sphere-formation technique has been used to demonstrate that putative cancer stem cells from freshly isolated brain tumors [20] or breast tumors [21] have a non-adherent phenotype and form 'neurospheres' that are enriched in $\mathrm{CD} 133^{+}$cells, and 'mammospheres' that are enriched in $\mathrm{CD}_{4} 4^{+}$and CD24 cells. When plated in serum-free suspension culture systems, tumorspheres derived from human PCa cell lines possess chemoresistant and CSCs properties [22]. Thus, the serum-free sphere culture protocol is one approach for enriching putative CSCs from a variety of established cell lines in vitro.

Radiotherapy and some chemotherapeutic agents can induce DNA damage, resulting in the activation of cell death pathways, culminating in tumor cell death. However, efficient DNA repair mechanisms and active anti-apoptotic pathways, as well as the effects of the cell cycle, can render these treatments ineffective on tumors. This is a well-established phenomenon and there is evidence of this in tumor stem cells from solid tumors [23]. Bao and colleagues reported that after irradiating $\mathrm{CD}_{133^{+}}$glioma stem cells, there was an increase in DNA damage checkpoint activation and more efficient DNA repair relative to CD133- cells [13]. In hepatocellular carcinoma, $\mathrm{CD}_{133^{+}}$cells were resistant to doxorubicin and fluorouracil, and this was attributed to expression of bcl-2, Akt and PKB, components of an anti-apoptotic survival pathway [24]. Therefore, it is reasonable to speculate that chemoradiotherapy could be effectively used to identify and enrich CSCs within the tumor by eliminating chemo- and radio-sensitive cells. In the light of these previous studies, we used serum-free sphere cultures, chemotherapy and radiation therapy to enrich prostate CSCs in order to investigate their properties.

In the DU145 cell line, a small population of $\mathrm{CD} 133^{+} / \mathrm{CD}_{4} 4^{+}$cells $(0.1 \%)$ was identified by flow cytometric analysis, with no detectable CD133 ${ }^{+} / \mathrm{CD}_{4} 4^{+}$cells in PC-3 or LNCaP cell lines when they were cultured under normal conditions, similar to the results of a study by Pfeiffer and co-workers [25]. Interestingly, when these three PCa cell lines were cultured in defined SFM, the proportions of $\mathrm{CD} 133^{+} / \mathrm{CD}_{4} 4^{+}$cells were $10.3 \%$ and $3 \%$ in DU145 and PC- 3 cultures, respectively.

In contrast, $\mathrm{CD} 133^{+} / \mathrm{CD} 44^{+}$cells were still undetectable among LNCaP cells maintained in either SSM or SFM. The LNCaP cell line is an androgen-responsive $\mathrm{PCa}$ epithelial cell line expressing the androgen receptor (AR), while a few studies have shown that prostate CSCs do not express the AR [10, $18,26]$, and $\mathrm{CD} 133^{+} \mathrm{PCa}$ cells were originally reported to be $\mathrm{AR}^{-}$[15]. CD44+ cells from human PCa cell lines are also $\mathrm{AR}^{-}$[18]. Nevertheless, other studies suggest that the $\mathrm{CD} 133^{+}$cells responsible for tumor propagation and progression are $\mathrm{AR}^{+}$and therefore are direct targets for androgen stimulation [27]. Thus, it is evident that the relationship between androgens and prostate CSCs is still unclear, and further studies are required to clearly define a role for the $\mathrm{AR}$ and androgens in prostate CSCs.

In our study, LNCaP cells did not form obvious suspension spheres following culture in serum-free medium and no $\mathrm{CD} 133^{+} / \mathrm{CD} 44^{+}$cells were detected by flow cytometric analysis. Only the surviving DU145 and PC-3 cells could form suspended spheres of cells when cultured in the serum-free medium, and the proportion of $\mathrm{CD}_{133^{+}} / \mathrm{CD} 44^{+}$cells in DU145 $(10.3 \%)$ was higher than that of PC-3 $(3.0 \%)$. Thus, we selected DU145 cells for chemoradiotherapy enrichment and evaluated the stem cell properties of $\mathrm{CD} 133^{+} / \mathrm{CD}_{4} 4^{+}$cells in DU145.

Chemotherapy and radiation therapy were employed to enrich prostate CSCs. Following chemotherapy, prostate CSCs accounted for $9.8 \%$ of the DU145 population, while CSCs comprised $3.5 \%$ of the DU145 population after radiation therapy, demonstrating that prostate CSCs are radio- and chemo-resistant. It is thus reasonable to speculate that chemotherapy drugs and radiation treatment can be effectively used to identify and enrich CSCs within the tumor by eliminating radio- and chemo-sensitive cells. Indeed, Du and colleagues cultured pancreatic cancer cell lines in gemcitabine with synchronous 
radiotherapy to obtain resistant subpopulations that were similar to CSCs [28]. To complement this, our study demonstrates that SFM culture, as well as chemotherapy and radiation therapy, is an effective approach to enriching prostate CSCs.

To evaluate the stem cell properties of $\mathrm{CD} 133^{+} / \mathrm{CD}_{4}{ }^{+}$cells in DU145 further, colony-formation tests, cell invasion assays, and tumor xenografts in BALB/c nude mice were used. CD133 ${ }^{+} / \mathrm{CD}_{4}{ }^{+}$DU145 cells had enhanced colony-formation and invasive abilities in vitro, and were more tumorigenic in vivo. CD133+/CD44+ DU145 cells generated larger subcutaneous tumors that exhibited shorter time latency compared with parental cells, indicating that $\mathrm{CD} 133^{+} / \mathrm{CD} 44^{+}$cells in DU145 have the characteristics of CSCs.

These results demonstrate the presence of $\mathrm{CD} 133^{+} / \mathrm{CD}_{4} 4^{+}$prostate CSCs in several established PCa cell lines, the proportion of which can be further enriched by culture in SFM or by chemo- or radiotherapy. Finding novel therapies to override chemoradiation resistance in the prostate CSCs is the key to improve long-term results in PCa management.

\section{Abbreviations}

CSCs: cancer stem cells; PCa: prostate cancer; FACS: fluorescence-activated cell sorting; SFM: serum-free medium; CFE: colony-formation efficiency; TV: tumor volume; SSM: serum-supplemented medium; MTT: methyl thiazolyl tetrazolium.

\section{Competing Interests}

The authors have declared that no competing interest exists.

\section{References}

1. Jemal A, Bray F, Center MM, et al. Global cancer statistics. CA Cancer J Clin. 2011; 61: 69-90.

2. Siegel R, Naishadham D, Jemal A. Cancer statistics, 2012. CA Cancer J Clin. 2012; 62: 10-29.

3. Grubb RL 3rd, Kibel AS. Prostate cancer: screening, diagnosis and management in 2007. Mo Med.2007; 104: 408-413.

4. Sagar J, Chaib B, Sales K, et al. Role of stem cells in cancer therapy and cancer stem cells: a review. Cancer Cell Int. 2007; 7: 9.

5. Reya T, Morrison SJ, Clarke MF, et al. Stem cells, cancer, and cancer stem cells. Nature. 2001; 414: 105-111.

6. Giordano A, Fucito A, Romano G, et al. Carcinogenesis and environment: the cancer stem cell hypothesis and implications for the development of novel therapeutics and diagnostics. Front Biosci. 2007; 12: 3475-3482.

7. Charafe-Jauffret E, Ginestier C, Iovino F, et al. Breast cancer cell lines contain functional cancer stem cells with metastatic capacity and a distinct molecular signature. Cancer Res. 2009; 69: 1302-1313.

8. Galli R, Binda E, Orfanelli $U$, et al. Isolation and characterization of tumorigenic, stem-like neural precursors from human glioblastoma. Cancer Res. 2004; 64: 7011-7021.

9. Kim CF, Jackson EL, Woolfenden AE, et al. Identification of bronchioalveolar stem cells in normal lung and lung cancer. Cell. 2005; 121: 823-835.

10. Collins AT, Berry PA, Hyde C, et al. Prospective identification of tumorigenic prostate cancer stem cells. Cancer Res. 2005; 65: 10946-10951.

11. Dean M, Fojo T, Bates S. Tumour stem cells and drug resistance. Nat Rev Cancer. 2005; 5: 275-284.
12. Baumann M, Krause M, Hill R. Exploring the role of cancer stem cells in radioresistance. Nat Rev Cancer. 2008; 8: 545-554.

13. Bao $\mathrm{S}, \mathrm{Wu} \mathrm{Q}, \mathrm{McLendon} \mathrm{RE}$, et al. Glioma stem cells promote radioresistance by preferential activation of the DNA damage response. Nature. 2006; 444: 756-760.

14. Clarke MF, Dick JE, Dirks PB, et al. Cancer stem cells--perspectives on current status and future directions: AACR Workshop on cancer stem cells. Cancer Res. 2006; 66: 9339-9344.

15. Richardson GD, Robson CN, Lang SH, et al. CD133, a novel marker for human prostatic epithelial stem cells. J Cell Sci. 2004; 117: 3539-3545.

16. Wei C, Guomin W, Yujun L, et al. Cancer stem-like cells in human prostate carcinoma cells DU145: the seeds of the cell line? Cancer Biol Ther. 2007; 6: 763-768.

17. Miki J, Furusato B, Li H, et al. Identification of putative stem cell markers, CD133 and CXCR4, in hTERT-immortalized primary nonmalignant and malignant tumor-derived human prostate epithelial cell lines and in prostate cancer specimens. Cancer Res. 2007; 67: 3153-3161.

18. Patrawala L, Calhoun T, Schneider-Broussard R, et al. Highly purified CD44+ prostate cancer cells from xenograft human tumors are enriched in tumorigenic and metastatic progenitor cells. Oncogene. 2006; 25: 1696-1708.

19. Maitland NJ, Collins AT. Prostate cancer stem cells: a new target for therapy. J Clin Oncol. 2008; 26: 2862-2870.

20. Singh SK, Hawkins C, Clarke ID, et al. Identification of human brain tumor initiating cells. Nature. 2004; 432: 396-401.

21. Dey D, Saxena M, Paranjape AN, et al. Phenotypic and functional characterization of human mammary stem/progenitor cells in long term culture. PLoS One. 2009; 4: e5329.

22. Zhang L, Jiao M, Li L, et al. Tumorspheres derived from prostate cancer cells possess chemoresistant and cancer stem cell properties. J Cancer Res Clin Oncol. 2012; 138: 675-686.

23. Lang SH, Frame FM, Collins AT. Prostate cancer stem cells. J Pathol. 2009; 217: 299-306.

24. Ma S, Lee TK, Zheng BJ, et al. CD133+ HCC cancer stem cells confer chemoresistance by preferential expression of the Akt/PKB survival pathway. Oncogene. 2008; 27: 1749-1758.

25. Pfeiffer MJ, Schalken JA. Stem cell characteristics in prostate cancer cell lines. Eur Urol. 2010; 57: 246-255.

26. Rajasekhar VK, Studer L, Gerald W, et al. Tumour-initiating stem-like cells in human prostate cancer exhibit increased NF-kappaB signalling. Nat Commun. 2011; 2: 162.

27. Vander Griend DJ, Karthaus WL, Dalrymple S, et al. The role of CD133 in normal human prostate stem cells and malignant cancer-initiating cells. Cancer Res. 2008; 68: 9703-9711.

28. Du Z, Qin R, Wei C, et al. Pancreatic cancer cells resistant to chemoradiotherapy rich in "stem-cell-like" tumor cells. Dig Dis Sci. 2011; 56: 741-750. 